\title{
Pumping System Analysis for Upgrading Works in a Government Owned Water Treatment Plant in Malaysia
}

\author{
Mohmad Asari Daud ${ }^{1}$, Zaini Ujang ${ }^{2}$ and Megat Johari Megat Mohd Noor ${ }^{3}$ \\ 1. Waterbez Sdn Bhd, Jalan Bandar 11, Taman Melawati, Kuala Lumpur 53100, Malaysia \\ 2. Menara Razak, University of Technology Malaysia, Kuala Lumpur 54100, Malaysia \\ 3. Malaysia-Japan International Institute of Technology, University of Technology Malaysia, Kuala Lumpur 54100, Malaysia
}

\begin{abstract}
Pumping system analysis can be used together with a decision support system to provide information for efficient pumping system operation or system refurbishment and upgrading. The actual operation condition of the water supply system needs to be ascertained. This paper will share experience by the authors in determining the actual pump performance through measurement of flow and pressure in the system. The incremental increase in pressure is achieved by varying head loss induced to the system by valve throttling. Integrating the Bernoulli's principles of the geodetic, static and dynamic energy, and input power data will enable the analysis of energy input and output and hence arriving to pump efficiency values. This method offers the most accurate operation conditions for refurbishment systems to endure. The on-site measurements will allow the determination of the averaged actual friction coefficient which includes the effect of system deterioration and fittings conditions. This information will be used to determine the expected duty point of an upgrading system more precisely. The study highlighted the actual pump operating efficiencies for an old pumping system installation.
\end{abstract}

Key words: Water treatment plant, operation, pump performance, upgrading.

\section{Introduction}

This study is aimed at determining the actual duty point of water pumpset and analysing its performance using basic principles of Bernoulli. However most facilities installed in Government water treatment plants are ageing and the performance has deteriorated and needs to be evaluated in order to determine the appropriate works for upgrading.

Correct arrangement and measuring methods are necessary to derive the geodetic, dynamic and static energy in the system. This information forms the basis for correct design of rehabilitation components where designing pumpset forms part of the process. Unlike designing a new system where the assumptions were always validated against laboratory or factory testing, designing an upgrading of existing system can always

Correspondence author: Mohmad Asari Daud, Ph.D. candidate, professional engineer, main research: water treatment upgrading. be erroneous if the assumptions made were wrong and not representative of the actual site conditions. This study offers accurate way to determine pumping system duty point of upgrading condition instead of depending on assumptions provided in design software and desk studies.

In an old system, pigging works may be carried out before designing a new system to obtain energy efficient system rather than over designing which leads to inefficient operation. Pigging or other forms of pipe cleaning may result in improvement of operation efficiency and can be immediately benefitted for the upgrading design.

\section{Background}

Recent development of information technology has brought in several software programs to derive accurate duty point for upgrading pump capacity in water treatment plants [1]. In deriving the design duty point, designers always depend on several 
assumptions such as friction losses, internal pipe sizes, minor losses due to specials and fittings and other engineering considerations.

In the public water treatment plants, unlike those run by private water companies, the level of maintenance is somehow less focused as profit and efficiency have not been given ample emphasis. Hence, improvements in its efficiency have great potential as it has not been fully explored. Therefore, it is important to assess pumping system performance before carrying out upgrading works. As the famous management guru, Peter Drucker says, "Anything you can't measure it, you can't improve it." [2].

Pumping consumes the greatest quantity of electrical energy in water treatment operations by far. Indeed, pumping often forms at least $40 \%$ of operation cost, as experienced at this water treatment plant, making the knowledge of pump performance a key success factor in managing the water treatment plant operations. The essential parameters of a pump's performance consist of total differential hydraulic pressure, power, efficiency and volumetric flow rate. Therefore, step one of pumping system refurbishment is to be able to effectively measure these parameters, with the aim of upgrading the pumping system to be able to operate at optimum costs.

\section{Methodology}

(1) The measurement of Voltage (V), Current (A), $\mathrm{PF}$ (Power Factor) is done at site using multi tester equipment to read the input voltage, current and $\mathrm{PF}$ at designated points.

(2) The measurement of pressure is done using calibrated pressure gauges whereas measurements of flows are done using calibrated ultrasonic flowmeter.

(3) Ultrasonic flowmeter must have adequate straight length both upstream and downstream to maintain the accuracy of the flowmeter.

(4) Results were tabulated and total head of the operating pump is calculated using Bernoulli's formula as follows:

$$
H_{t}=\left(P_{d}-P_{s}\right)+\left(Z_{d}-Z_{s}\right)+\left(\frac{V_{d}{ }^{2}-V_{s}{ }^{2}}{2 g}\right)
$$

where,

$\mathrm{H}_{\mathrm{t}}=$ Total head (m);

$\mathrm{V}_{\mathrm{s}}=$ Velocity at suction $(\mathrm{m} / \mathrm{s})$;

$\mathrm{V}_{\mathrm{d}}=$ Velocity at delivery $(\mathrm{m} / \mathrm{s})$;

$Z_{d}-Z_{s}=$ difference in pressure gauge level at suction discharge $(\mathrm{m})$;

$\mathrm{P}_{\mathrm{d}}-\mathrm{P}_{\mathrm{s}}=$ difference in pressure at suction discharge (m).

(5) Arrangement of Instruments

The most important and difficult task in performing this study is to find a suitable location for the measurement of flow and pressure.

1. Flowmeter location must comply the requirement of manufacturers in terms of providing the adequate straight length (straight running pipe). Panametric Model PT878 which was used requires $10 \times$ pipe diameter for the upstream and $5 \times$ pipe diameter for downstream [3].

2. For collecting data for pump curve, the pressure sensor must be positioned between the pump unit and the throttled delivery valve (as shown in Fig. 1).

3. For collecting for system curve, the pressure sensor must be located after the throttled valve (as shown in Fig. 1).

4. Valve throttling must be done slowly since the pressure and flow changes will take some time to stabilise. Caution must be taken to avoid pump damage or stoppage due to excessive vibration.

\section{Results and Analysis}

\subsection{Tabulation of Data Collected}

The hydraulic components data collected are shown in Table 1.

Motor components data and water power data are simultaneously collected and shown in Table 2 .

Table 3 shows the important information of the pump tested. The data from Tables 1 and 2 can be presented in graphical as shown in Fig. 2. 


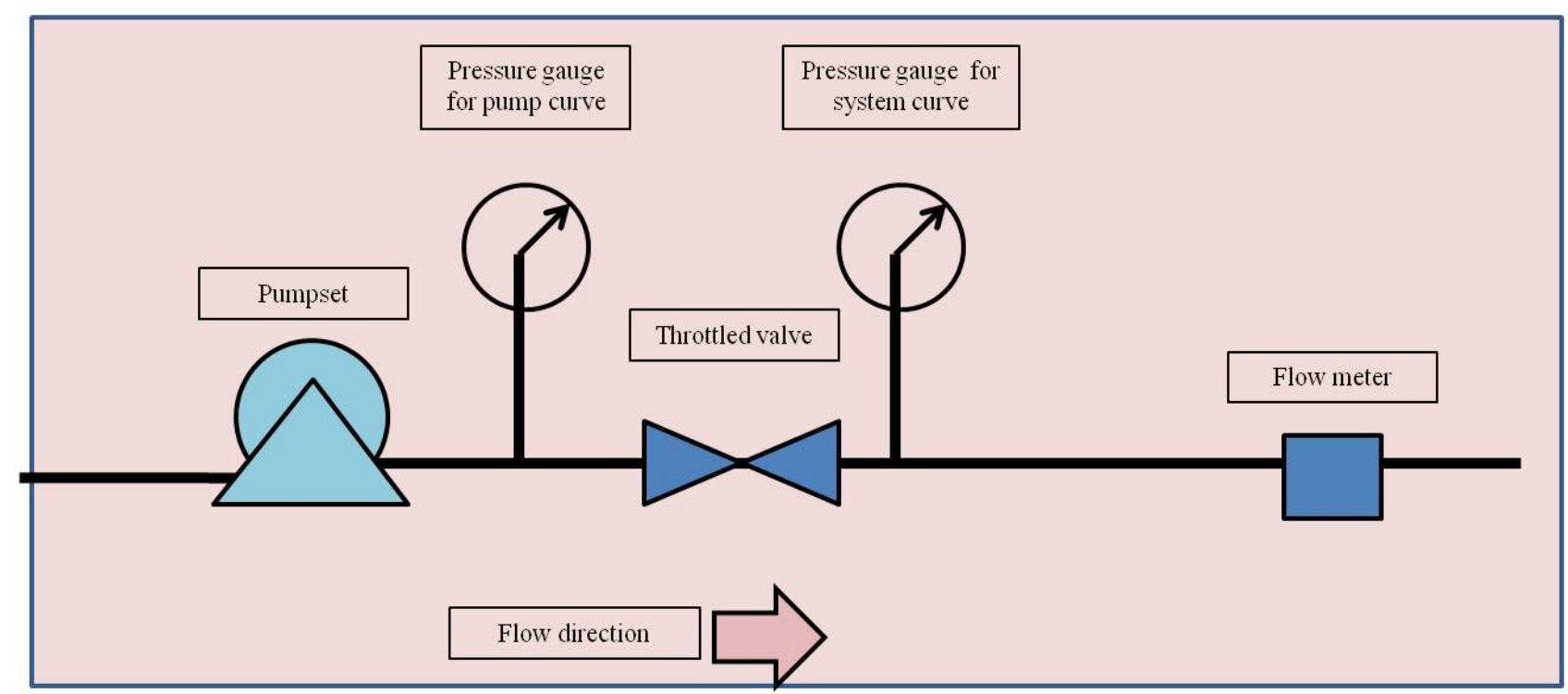

Fig. 1 Positions of pressure gauge for construction of pump and system curve.

Table 1 Calculation of total pressure at different flows.

\begin{tabular}{|c|c|c|c|c|c|c|c|c|c|c|c|c|c|}
\hline \multirow{3}{*}{$\begin{array}{l}\text { No. of } \\
\text { point }\end{array}$} & \multirow{3}{*}{$\begin{array}{l}\text { Capacity } \\
\text { flow rate } \\
\mathrm{m}^{3} / \mathrm{h}\end{array}$} & \multicolumn{4}{|c|}{ Pressure reading } & \multicolumn{2}{|c|}{$\begin{array}{l}\text { Gauge height } \\
\text { from pump c/line }\end{array}$} & \multicolumn{4}{|c|}{ Velocity head $\left(\mathrm{V}^{2} / 2 \mathrm{~g}\right)$} & \multicolumn{2}{|c|}{$\begin{array}{c}\text { Level } \\
\text { difference in } \\
\text { suction tank }\end{array}$} \\
\hline & & \multicolumn{2}{|c|}{ D (Delivery) } & \multicolumn{2}{|c|}{ S (Suction) } & $\mathrm{D}$ & $\mathrm{S}$ & $\mathrm{S}$ & $\mathrm{D}$ & Difference & Total head & Start & Stop \\
\hline & & (bar) & $(\mathrm{m})$ & (bar) & $\mathrm{m}$ & $\mathrm{mm}$ & $\mathrm{mm}$ & $\mathrm{m}$ & $\mathrm{m}$ & $\mathrm{m}$ & metres & $\mathrm{mm}$ & $\mathrm{mm}$ \\
\hline F.O & 480.00 & 2.20 & 22.46 & 0.10 & 1.02 & 0 & -230 & 0.376 & 0.918 & 0.542 & 22.21 & 0 & 0 \\
\hline 2 & 320.00 & 2.40 & 24.50 & 0.10 & 1.02 & 0 & -230 & 0.167 & 0.408 & 0.241 & 23.95 & 0 & 0 \\
\hline 3 & 120.00 & 2.50 & 25.53 & 0.10 & 1.02 & 0 & -230 & 0.024 & 0.057 & 0.034 & 24.77 & 0 & 0 \\
\hline F.C & 0.00 & 3.1 & 31.65 & 0.10 & 1.02 & 0 & -230 & 0.000 & 0.000 & 0.000 & 30.86 & 0 & 0 \\
\hline
\end{tabular}

F.O: Fully open; F.C: Fully closed; 2, 3: Position of valve with flow between $1 / 3$ to $2 / 3$ of F.O flows.

Table 2 Calculation water power and efficiency.

\begin{tabular}{|c|c|c|c|c|c|c|c|c|c|}
\hline \multirow{3}{*}{$\begin{array}{l}\text { No. of } \\
\text { points }\end{array}$} & \multirow{2}{*}{$\begin{array}{l}\text { Capacity } \\
\text { flow rate }\end{array}$} & \multicolumn{3}{|c|}{$\begin{array}{cl}\text { Electric Motor }(50 \mathrm{~Hz}) \\
\end{array}$} & \multirow{2}{*}{-Time } & \multirow{2}{*}{$\begin{array}{l}\text { WHP (Water } \\
\text { Horse Power) }\end{array}$} & \multirow{2}{*}{$\begin{array}{l}\text { BHP (use } \eta \\
\text { motor }=90 \% \text { ) }\end{array}$} & \multirow{2}{*}{ Input } & \multirow{2}{*}{$\begin{array}{l}\text { Pumpset } \eta \\
\text { (calculated) }\end{array}$} \\
\hline & & Current & $\mathrm{PF}$ & Voltage & & & & & \\
\hline & $\mathrm{m}^{3} / \mathrm{h}$ & Amp & $\mathrm{PF}$ & Volt & $\min$. & $\mathrm{kW}$ & $\mathrm{kW}$ & $\mathrm{kW}$ & $\%$ \\
\hline F.O & 480.00 & 102.20 & 0.89 & 425.00 & 0 & 29.05 & 32.28 & 66.95 & 48 \\
\hline 2 & 320.00 & 100.60 & 0.89 & 424.80 & 0 & 20.89 & 23.21 & 65.87 & 35 \\
\hline 3 & 120.00 & 99.79 & 0.89 & 425.20 & 0 & 8.10 & 9.00 & 65.41 & 14 \\
\hline F.C & 0.00 & 0.00 & 0.00 & 0.00 & 0 & 0.00 & 0.00 & 0.00 & 0 \\
\hline
\end{tabular}

Table 3 Pumpset information.

\begin{tabular}{lllll}
\hline Pump type & Motor type & Speed & Pipe delivery dia. & Pipe suction dia. \\
\hline Vertical, Weir & Slip Ring & $1,450 \mathrm{rpm}$ & $150 \mathrm{~mm}$ & $200 \mathrm{~mm}$ \\
\hline
\end{tabular}




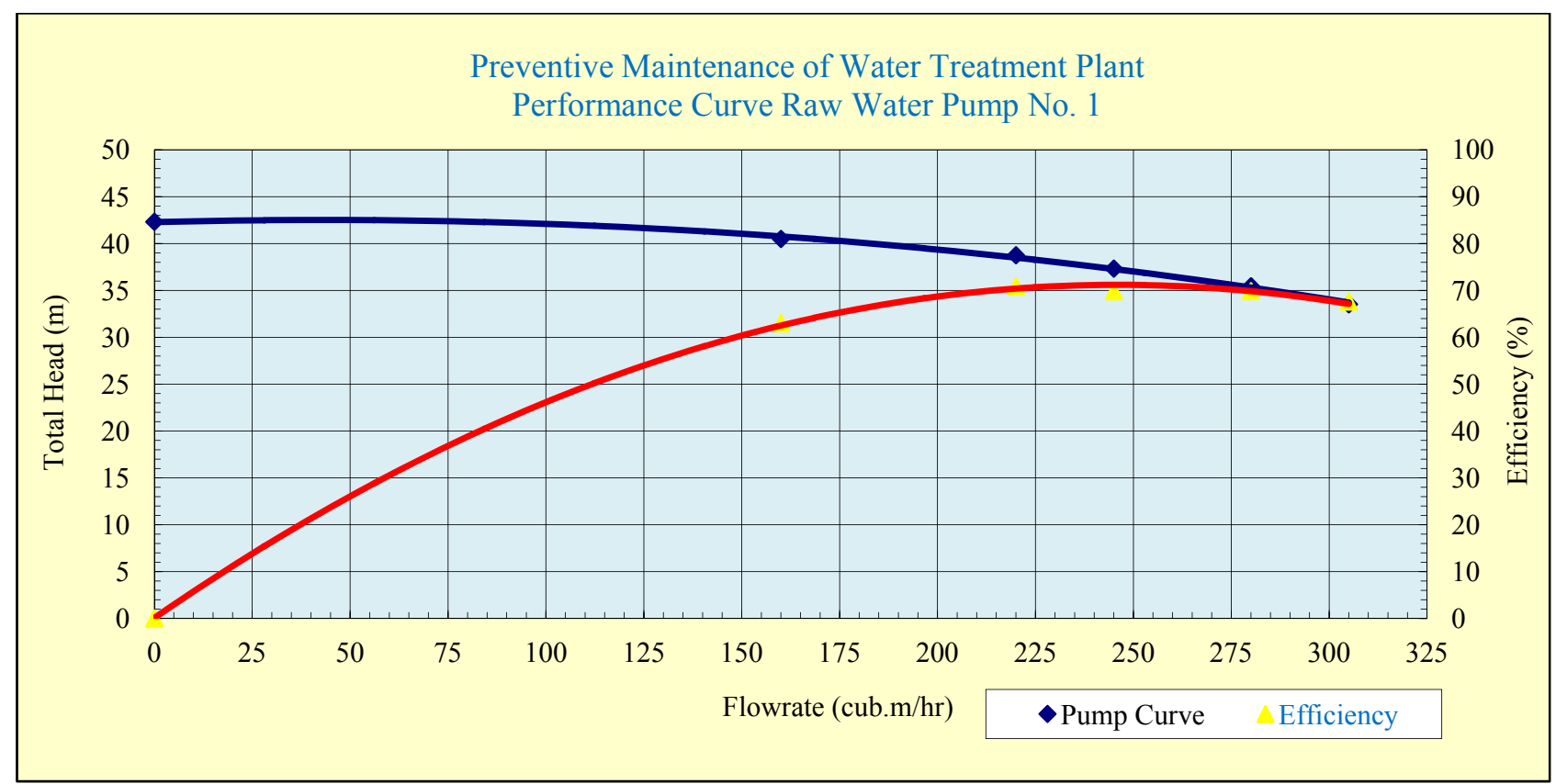

Fig. 2 Plotting of pump and efficiency curves.

\subsection{Calculating Pump Efficiency}

Pump efficiency is defined by the ratio of the brake horse power and the input power as shown in the Eq. (2):

$$
\eta=\frac{B H P}{P_{i}}
$$

where,

$$
\begin{gathered}
\eta=\text { pumpset efficiency; } \\
\text { BHP = brake horse power; } \\
\mathrm{P}_{\mathrm{i}}=\text { input power. }
\end{gathered}
$$

For three-phase installation,

$$
P_{i}=\sqrt{ } 3 \mathrm{VI} \cos \varnothing
$$

where,

$$
\begin{aligned}
& P_{i}=\text { input power }(W) ; \\
& V=\text { RMS voltage }(V) ; \\
& I=\text { RMS current }(A) ; \\
& \cos \varnothing=\text { Power factor; }
\end{aligned}
$$

RMS is root mean square .

Calculating the brake horse power,

$$
\mathrm{BHP}=\frac{\mathrm{WHP}}{\eta}
$$

where,

BHP $=$ brake horse power $(\mathrm{kW})$; WHP $=$ water horse power $(\mathrm{kW})$;

$$
\eta=\text { efficiency of pumpset. }
$$

To calculate WHP:

$$
\mathrm{WHP}=\frac{\mathrm{QH}_{\mathrm{t}}}{367}
$$

where,

WHP $=$ water horse power $(\mathrm{kW})$;

$$
\mathrm{Q}=\text { flow }\left(\mathrm{m}^{3} / \mathrm{h}\right) \text {; }
$$

$\mathrm{H}_{\mathrm{t}}=$ total head (m), derived using Bernoulli's principle as in Eq. (1).

According to UNEP [4], the efficiency of motors changes as loading varies as shown in Fig. 3. However from the graph, 73-100 HP motor has stable high efficiency until it is less than $20 \%$ full load and for $15.25 \mathrm{HP}$ it is up to $40 \%$ full load. Hence, it is quite safe to assume efficiency of $90 \%$ for motors in the analysis at the water treatment plant, provided the motors are in such range of horse power. Hence the pump efficiency can be derived once the combined efficiency is known.

\section{Discussion and Recommendations}

The use of ultrasonic flowmeter together with pressure logger provided the data required for the pumping system analysis. This portable flow meter, a compact transit time (time of flight) portable flow 


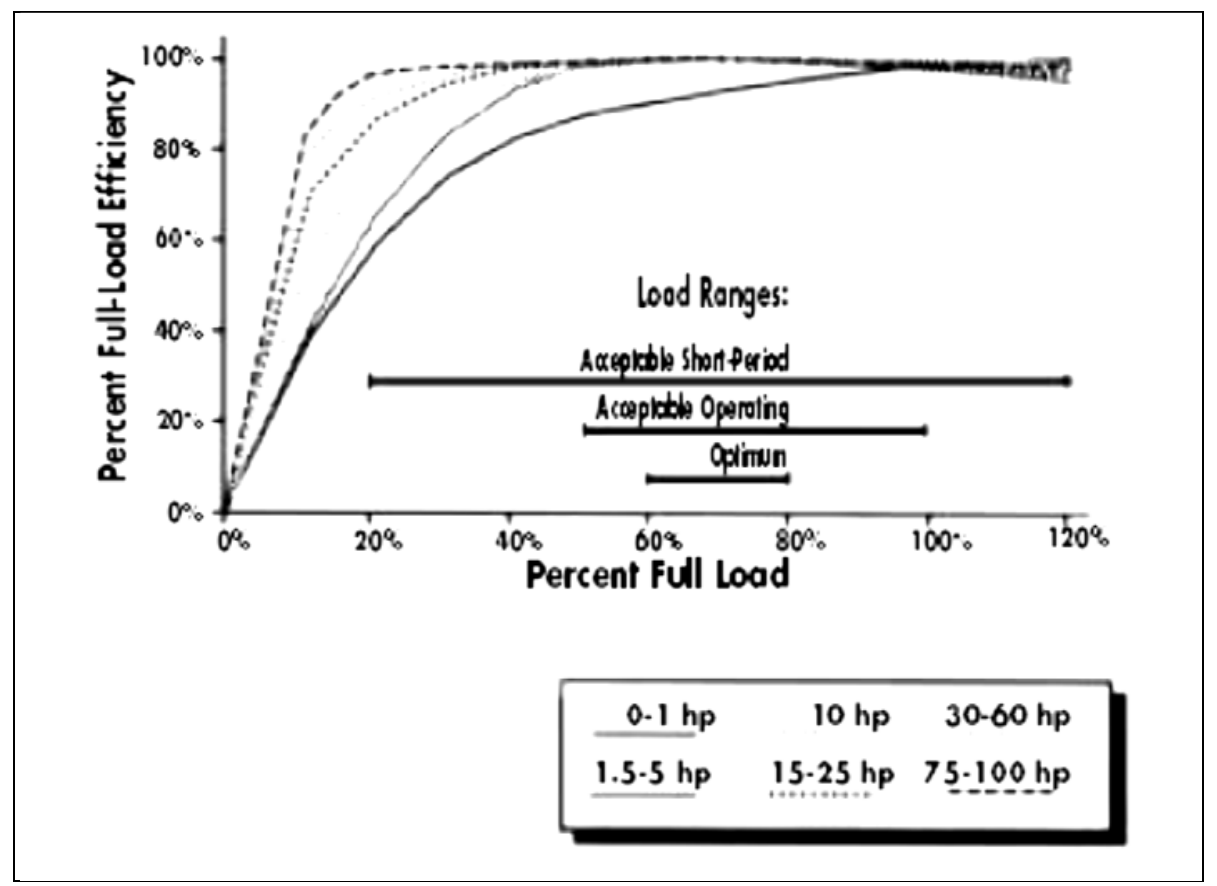

Fig. 3 Motor Efficiencies against loading [4].

meter, is suitable for a wide range of non-invasive flow measurement applications. Its clamping fixtures can suit most types of surfaces and environment. This clamp-on flow meter is handy since it can be easily installed and capable to provide data of flow within minutes [3]. However, it is imperative to key in correct information needed for the flowmeter to $\log$ and process.

From the data collected, collated and analysed, it was evident that the pumpset was running at low efficiencies, from about $15 \%$ to less than $50 \%$. Although the method did not differentiate the efficiency of pumps from the motors, it gave a representation of the status of the system where energy consumption was high due to low efficiency of the pumpset.

There can be many possible reasons. McNally Institute [5] listed as follows:

- Impeller conditions;

- Packing or mechanical seal;

- Wear rings and impeller clearances improper;

- Bypass line installed from the discharge side of the pump to the suction piping or valve not drop tight;
- Running the pump with a throttled discharge valve;

- Eroded or corroded internal pump passages which cause fluid turbulence;

- Any restrictions in the pump or piping passages such as product build up, a foreign object, or a stuck check valve;

- Over lubricated or over loaded bearings;

- Misalignment between the pump and driver;

- Pipe strain;

- Impeller imbalance;

- Bent shaft;

- Closed fitting bushing;

- Loose hardware;

- Protruding gasket rubbing against the mechanical seal;

- Cavitation;

- Harmonic vibration;

- Improper assembly of, the bearings, seal, wear rings, packing, seals etc.;

- Operating too far off from the best efficiency point of the pump;

- Water hammer and pressure surges; 
- Dynamic, non "O"-ring elastomers that cannot flex and roll, but must slide;

- Build-up of product on the inside of the stuffing box rubbing against the mechanical seal;

- Grease or lip seals rubbing the shaft next to the bearings;

- Over tightening packing or improper seal installation.

Proper maintenance is one way to overcome pump operating at low efficiency. Maintenance of water treatment plant may involve hundreds of items and pump set is one of the main equipment which needs to be maintained. To avoid oversight or delayed service and maintenance, proper preventive or scheduled maintenance needs to be implemented.

For big pump, it is viable to evaluate cost benefit analysis on changing parts such as impellers as it saves money as well as avoids water treatment plant disruption. For smaller pump, it is sometimes better to change the entire pump.

The assessment as done in this study is applicable to achieve other intentions such as:

- Determining the condition of pump just after installation;

- Producing system curve for the pumping system;

- Determining duty point of the pump; i.e. the point where the pump's curve crosses the system curve with different discharge conditions - valve fully close, throttled and with the discharge valve fully open;

- Assessing the match between "full flow" (flow delivered by the pump with the discharge valve fully open) and the actual design flow requirement;

- Assessing the implications of throttled discharge valves against open discharge valves;

- Assessing the option to optimise pump performance through trimming of the existing impeller or increasing the impeller's diameter;

- Fine tuning of pumping protocol to benefit the reduced operating costs;

- Assessing the flow variations occurring in the system as different active elements are deposited;

- Detecting and diagnosing other controls or performance problems;

It is possible to determine the financial saving and viability of changing pumpset as shown:

Assuming:

- Pump running at fully open valves having pumpset combined efficiency (of $90 \% \times 48 \%=43.2 \%$ ) using $67 \mathrm{~kW}$ (using data from Table 2);

- New pumpset with a combined efficiency of about $75 \%$ (power required $39 \mathrm{~kW}$ ).

Power saving $=28 \mathrm{~kW}$, hence one day saving is 672 kWh.

Assuming:

- Power rate of RM0.385/kWh, daily saving is RM258.72;

- Cost of supplying and installation of a new 40 $\mathrm{kW}$ pumps costs RM40,000, Payback period is expected to be 154 days (less than 6 months).

This proves the viability of changing the pumpset at the water treatment plant. The additional benefit is better service from a new pumpset.

Papa \& Radulj [6] mentioned that there are commonly two methods for testing pump performance and efficiency: conventional and thermodynamic. Each method, when applied under the right conditions, can yield accurate results. In comparison the later method does not require the straight lengths for installation of equipment. However it requires an accurate method of measuring the change in temperature as shown in Fig. 4.

This method is proven to be comparable to the other method which is the thermodynamic method. This method applies the values of flow and pressure to the basic principles of Bernoulli while thermodynamic method relies on small change in temperature which can be measured without interruptions.

Thermodynamic method determines the flow rate by exploring the hydraulic efficiency $\left(\eta_{\mathrm{H}}\right)$ from the Eq. (6) [8]:

$$
\eta_{\mathrm{H}}=\frac{\text { OUT }}{\mathrm{IN}}=\frac{\text { Water Power }}{\text { Shaft Power }}=\frac{\rho \mathrm{gHq}}{\mathrm{P}_{\mathrm{s}} \eta_{\mathrm{m}}}
$$




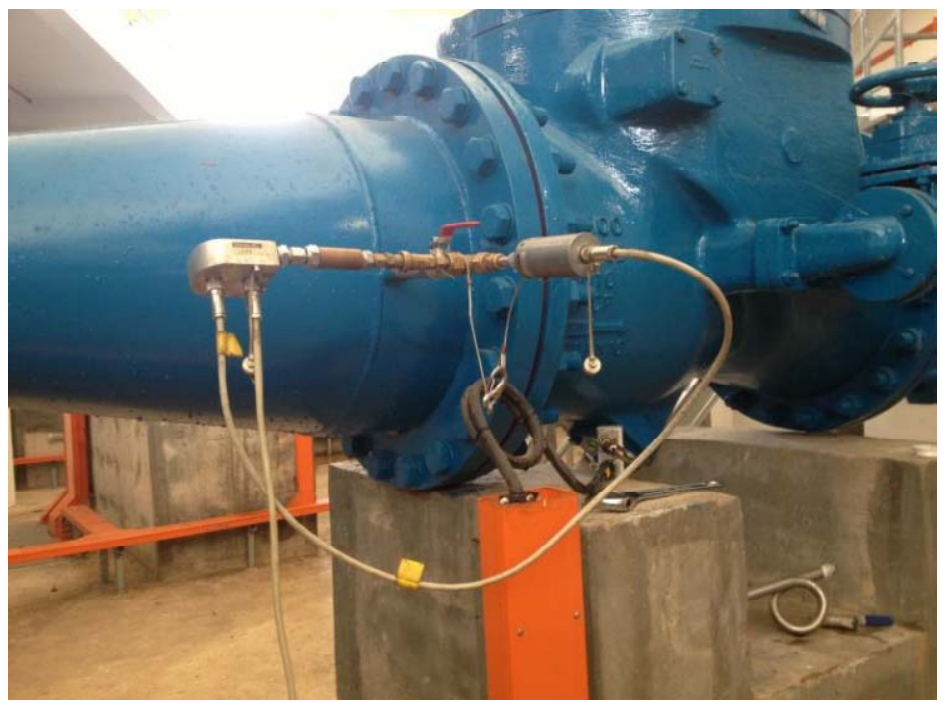

Fig. 4 Thermodynamic method of conducting pump test [8].

where $\eta_{H}$ is the hydraulic efficiency, $\eta_{m}$ is the mechanical efficiency, $\mathrm{H}$ is the total head ( $\mathrm{m})$, $\mathrm{q}$ is the flow $\left(\mathrm{m}^{3} / \mathrm{s}\right)$ and $\mathrm{P}_{\mathrm{s}}$ is the pump power.

Expanding Eq. (6):

$$
\eta_{\mathrm{H}}=\frac{\text { OUT }}{\text { IN }}=\frac{\text { OUT }}{\text { OUT }+ \text { LOSSES }}=\frac{1}{1+\frac{\text { LOSSES }}{\text { OUT }}}
$$

where,

$$
\begin{aligned}
& \text { LOSSES }=\rho C_{\mathrm{P}} \Delta \mathrm{T} q \\
& \text { OUT }=\rho g H q
\end{aligned}
$$

Hence,

$$
\eta_{\mathrm{H}}=\frac{1}{1+\frac{\rho C_{\mathrm{P}} \Delta \mathrm{Tq}}{\rho \mathrm{gg \textrm {H }}}}=\frac{1}{1+\frac{C_{\mathrm{P}} \Delta \mathrm{Tq}}{\mathrm{gH}}}
$$

where,

$\mathrm{C}_{\mathrm{P}}=$ specific heat capacity of fluid - from BS International Standards Organisation accepted definition (to measure fluid temperature to fully comply);

$\Delta \mathrm{T}=$ temperature differential across the pump $\left(\mathrm{m}^{\circ} \mathrm{K}\right)$.

Flow rate can then be calculated by the rearranging Eq. (6):

$$
\mathrm{q}=\frac{P_{\mathrm{s}} \eta_{\mathrm{m}} \eta_{\mathrm{H}}}{\rho g H}
$$

\section{Conclusion}

The study concluded that the method which utilised the Bernoulli's principles in determining the pump performance and eventually the pumping curves was essential to design the duty point for the pump selection of the refurbishment works. It was established that aging pump performs at very low efficiency and the efficiency dropped further whenever throttling was applied.

For design of system refurbishment, it is recommended that inverters are introduced to ensure pump duty points are maintained at optimum efficiencies. This is due to the limitation in determining accurately the actual duty point of a refurbished system. The inverters give the option for operation at optimum efficiency even though there are changes during installation period such as discovery of hidden valves etcetera. There are other possible factors that can affect the pump performance that might be found during the installation stage prior to test and commissioning. These new discoveries which are not evident during the analysis and design stages will be mitigated by adjusting the frequencies of the inverters.

Cost-benefit analysis can be easily carried out to justify changing of pumpsets. Example shows that at fully open valves a pumpset with combined efficiency of $48 \%$ using $67 \mathrm{~kW}$ can give a payback period of 6 months when changed to a $75 \%$ efficiency pumpset.

Alternatively, this procedure is also useful in conducting routine assessment of pumpset efficiency 
which is recommended to be carried out frequently according to the size of pumpsets [9]. Managers may establish routine schedules for asset management activities such as lubrication or bearing replacement. When it comes to pump testing for purposes of controlling energy usage, it is more practical to consider pumps inspection on the basis of the energy consumption, noting that the amount of energy consumed by pumps increases with the size of the pump and its motor [9].

\section{References}

[1] Hydraulic Institute. 2019. "Free Pump Software." [Online] Available at: http://pumps.org/Education/Free_Pump_Software.aspx.

[2] Shore, J. 2014. "These 10 Peter Drucker Quotes May Change Your World.” Entrepreneur [Online]. Available at: https://www.entrepreneur.com/slideshow/299936.

[3] RS Hydro. 2019. "PT878 Panametrics Portable Ultrasonic Flowmeter." [Online]. Available at: https: //www.rshydro.co.uk/flow-meters/ultrasonic-flow-meters/ portable-flow-meters/panametrics-pt878-flowmeter/.

[4] UNEP. 2006. "Energy Efficiency Guide for Industry in Asia." [Online] Available at: www.energyefficiencyasia.org.

[5] McNally Institute. 2019. "What Do We Mean by Pump Efficiency?" [Online] Available at: http://www.mcnallyinstitute.com/06-html/6-01.html.

[6] Papa, F. and Radulj, D. 2013. "Thermodynamic Method Used for Pump Performance and Efficiency Testing Program." Environmental Science \& Engineering Magazine 26: 44-8. [Online] Available at: http://hydratek.com/wp-content/uploads/2012/04/Results released of Ontario-wide pump performance and efficiency testing program.pdf.

[7] Bioenergy Value. 2017. "P22 Thermodynamic Pump Performance Testing and Monitoring."

[8] Clifford, T. 2018. "Conventional Testing vs. the Thermodynamic Model." [Online] Available at: https://www.pumpsandsystems.com/conventional-testingvs-thermodynamic-model.

[9] MPT. 2019. "Measuring the True Performance of Pumps in Operation." [Online] Available at: https://modernpumpingtoday.com/measuring-true-perfor mance-pumps-operation/. 